\title{
Risk Assessment of Heavy Metal Pollution in Sediments of the Fenghe River by the Fuzzy Synthetic Evaluation Model and Multivariate Statistical Methods
}

\author{
YANG Yang ${ }^{1}$, ZHOU Zhengchao ${ }^{2}$, BAI Yanying ${ }^{3, *}$, CAI Yimin ${ }^{1}$ and CHEN Weiping ${ }^{1}$ \\ ${ }^{1}$ State Key Laboratory of Urban and Regional Ecology, Research Center for Eco-Environmental Sciences, Chinese Academy of Sci- \\ ences, Beijing 100085 (China) \\ ${ }^{2}$ College of Environment and Tourism, Shaanxi Normal University, Xi'an 710062 (China) \\ ${ }^{3}$ Institute of Geographic Sciences and Natural Resources Research, Chinese Academy of Sciences, Beijing 100101 (China)
}

(Received August 5, 2015; revised February 5, 2016)

\begin{abstract}
Concentrations of heavy metals in 74 sediment samples from the Fenghe River, which originates from the north of the Qinling Mountains and flows through Xi'an, Shaanxi Province, China, were characterized by employing geographic information system (GIS) mapping, fuzzy synthetic assessment, and multivariate statistical analysis to determine the enrichment characteristics of heavy metals as well as their potential risks of pollution to sediments. $\mathrm{Al}, \mathrm{Cd}$, and $\mathrm{Co}$ were the major pollutants, with a high enrichment factor (EF) value. Heavy metal concentrations from samples near the paper plant were maintained at a high level. Significant enrichment of $\mathrm{Al}, \mathrm{Ba}, \mathrm{Cr}, \mathrm{Ni}, \mathrm{Pb}$, and $\mathrm{Co}$ was found in the midstream and downstream, while high concentration of $\mathrm{Cu}$ occurred in the headwater stream. Based on the cluster and principal component analyses, sediment metals mainly came from the paper plants, agronomic practices, natural sources, and tourism, with a contribution of $51.59 \%, 23.01 \%, 14.21 \%$, and $9.88 \%$, respectively. Sediment pollution assessment explored using fuzzy theory based on the entropy method and toxicity coefficient showed that 26, 32, and 11 sites fell into Class III (slightly polluted), Class IV (moderately polluted), and Class V (heavily polluted), respectively, and their scores of membership degree in the polluted level were on the rise, suggesting a relatively high degree of sediment metal pollution in the study area. Closely related to the excessive industrial and agricultural applications, metal pollution in sediment is necessary to be addressed in the Fenghe River.
\end{abstract}

Key Words: fuzzy theory, risk analysis, river ecosystem, sediment pollution, spatial analysis

Citation: Yang Y, Zhou Z C, Bai Y Y, Cai Y M, Chen W P. 2016. Risk assessment of heavy metal pollution in sediments of the Fenghe River by the fuzzy synthetic evaluation model and multivariate statistical methods. Pedosphere. 26(3): 326-334.

\section{INTRODUCTION}

As an important component of river systems, sediment is one of the largest containers and resources of harmful substances and acts as a major role in maintaining the normal aquatic habitats (Amorosi et al., 2013; Zhao and Li, 2013). In fluvial environments, sediments from the river function as a medium for aquatic flora and fauna to grow or as a pool to dispose of hazardous metals, as well as a pollutant reservoir for the surface water, groundwater and plants (Varol, 2011; Grygar et al., 2013). Metal pollution is of great concern due to their abundance, persistence, and toxicity in the aquatic environment (Tan et al., 2006; Zhang et al., 2014). High levels of sediment metals may impose a persistent burden on the natural growth of aquatic flora and fauna, cause the deterioration of water quality, and impair human health through the food chains
(Yang et al., 2009; Zeng and Wu, 2009). Heavy metals are continuously introduced into fluvial environments through mining, combustion residues, vehicle emissions, transportation, and some other human activities with rapid urbanization and industrialization all over the world (Subida et al., 2013; Wang et al., 2013; Zhang et al., 2014). Based on the enrichment factor (EF) (Lourenço et al., 2010), Viers (2009) revealed that the majority of the world river systems are seriously suffering from metal pollution, particularly in Asia (China and India), Europe, and North America. In the case of metals such as $\mathrm{Pb}$ and $\mathrm{Cd}$, the $\mathrm{EF}$ can be higher than 60 and 100, respectively (Viers, 2009; Varol, 2011). The study of Walling (2006) suggested that the climate change and biogeochemical cycle were closely related to the high level of sediment metals. Using the global sediment flux of $15 \times 10^{9} \mathrm{t}_{\text {year }}{ }^{-1}$ (Walling, 2006), the global metal flux transported by 
the river sediment from the continents to the oceans is approximately $23 \times 10^{3} \mathrm{t}_{\text {year }}{ }^{-1}$ for $\mathrm{Cd}, 916 \times 10^{3} \mathrm{t}$ year $^{-1}$ for $\mathrm{Pb}, 1140 \times 10^{3}$ t year $^{-1}$ for $\mathrm{Cu}, 1118 \times 10^{3}$ $\mathrm{t}_{\text {year }}{ }^{-1}$ for $\mathrm{Ni}, 338 \times 10^{3} \mathrm{t}_{\text {year }}{ }^{-1}$ for $\mathrm{Co}$, and 3123 $\times 10^{3} \mathrm{t} \mathrm{year}^{-1}$ for $\mathrm{Zn}$, respectively, and the values are on the rise (Viers, 2009).

The assessment of the pollution degree of sediment metals is important for risk management (Grygar et al., 2013; Zhang et al., 2014). Many methods have been established, yet some defects of these models simultaneously accompany. For instance, single factor index $\left(P_{i}\right)$, geo-accumulation index $\left(I_{\text {geo }}\right)$, and EF are suitable only for risk assessment of a single metal (Zeng and Wu, 2009; Varol, 2011; Amorosi et al., 2013), Nemerow index (NI) may overestimate the metal pollution degree (Zhao and Li, 2013), and pollution load index (PLI) emphasizes the spatial distribution of metals but ignores some metals with low concentration but highly toxicity (Yang et al., 2009). Potential risk index (RI) and back-propagation neural network (BPNN) model have widely been applied in the recent decades; however, weighting set may limit their applicability due to variation of the geochemical background values and classification criteria (Varol, 2011; Subida et al., 2013). To address this problem, fuzzy theory is introduced to assess and classify pollution degree of heavy metals (Lourenço et al., 2010). Based on membership functions, it is proved to be useful to settle the fuzzy characteristics of metal pollution degree with a gradual change from light to heavy (Tan et al., 2006).

Previous researches have largely focused on the metal pollution in sediments of many rivers and lakes in the economically developed areas of China, and revealed that anthropogenic activities contribute to the sediment pollution of $\mathrm{Cd}, \mathrm{Co}, \mathrm{Cu}, \mathrm{Ni}, \mathrm{Pb}$, and Zn (Viers, 2009; Yang et al., 2009; Zeng and Wu, 2009). The Fenghe River is one of the major sources of water supply in Xi'an, the largest city in Northwest China, and has undergone serious metal pollution in the river ecosystem owing to the rapid socioeconomic growth in the past few decades (Wang et al., 2013). However, little information is available about metal pollution in sediments of this area. Therefore, a systematic investigation and an objective assessment are necessary to properly manage the ecological risk in the sediments caused by hazardous metal pollution.

The aim of this study was to determine the enrichment characteristics of heavy metals as well as their potential risks of pollution in sediments, by employing geographic information system (GIS) mapping, fuzzy synthetic assessment, and multivariate statistical analysis.

\section{MATERIALS AND METHODS}

\section{Description of study area and sample analysis}

With a length of $81 \mathrm{~km}$, the Fenghe River $\left(108^{\circ} 35^{\prime}\right.$ $109^{\circ} 09^{\prime} \mathrm{E}, 33^{\circ} 50^{\prime}-34^{\circ} 20^{\prime} \mathrm{N}$ ) originates from the north of the Qinling Mountains and flows through Xi'an, Shaanxi Province of China. The annual mean discharge is $2.58 \times 10^{10} \mathrm{~m}^{3}$ year ${ }^{-1}$ with significant seasonal variations. As the largest tributary in the southern part of the Weihe River in the Yellow River basin (Fig. 1), the Fenghe River consists of 56 valleys and drains with an area of $1460 \mathrm{~km}^{2}$, transitioning between semi-arid and sub-humid zones in the northwest of China (Wang et al., 2013). Two sampling campaigns were conducted in late spring-summer (from May to August), including 32 sites in 2011 and 42 sites in 2012 (Fig. 1). All the sites were located using a global positioning system.

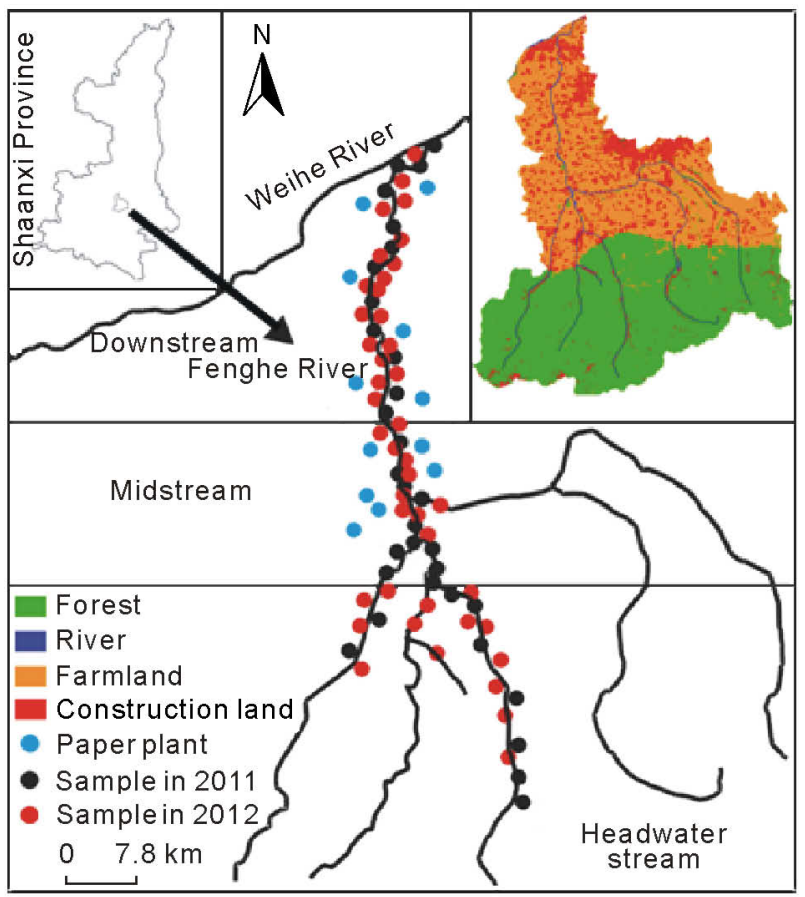

Fig. 1 Location of the study area and the distribution of sampling sites in the Fenghe River, flowing through Xi'an, Shaanxi Province of China, with land-use types shown in the top right corner.

At each site, five surface sediment $(2 \mathrm{~cm})$ samples were collected within an area of $2.5 \mathrm{~m}^{2}$ (Zeng and $\mathrm{Wu}$, 2009), using a gravity corer of $60 \mathrm{~cm}$ long and $6 \mathrm{~cm}$ internal diameter. The five samples were then mixed to form a composite sample (2000 g) for this site. Each sample was sealed in the polyethylene bags and stored in a cooled box $\left(4^{\circ} \mathrm{C}\right)$. The samples were air-dried, sieved through a 2-mm nylon mesh and then divided into four parts using a quartering method. One part of 
samples were then ground with a vibration mill and sieved through a $0.075-\mathrm{mm}$ mesh for chemical analysis.

Sediment $\mathrm{pH}$, loss on ignition (LOI), total organic carbon (TOC) and grain size were determined $\mathrm{u}-$ sing a glass electrode connected to a $\mathrm{pH}$ meter, a muffle furnace, the Phoenix-8000 TOC analyzer (Tekman Dohrmann, Mason, USA), and the Longbench Mastersizer 2000 (Malvern Instruments, London, UK), respectively. Sediment samples $(0.25 \mathrm{~g})$ were extracted with concentrated $\mathrm{HF}-\mathrm{HCl}-\mathrm{HNO}_{3}-\mathrm{HClO}_{4}$ (Zeng and $\mathrm{Wu}, 2009)$. Concentrations of $\mathrm{Al}\left(\mathrm{Al}_{2} \mathrm{O}_{3}\right), \mathrm{Ba}, \mathrm{Cr}, \mathrm{Mn}$, $\mathrm{V}, \mathrm{Zn}, \mathrm{P}$, and $\mathrm{K}$ were analyzed by inductively coupled plasma atomic emission spectroscopy (ICP-AES, Perkin-Elmer DV4300, Perkin-Elmer, Norwalk, USA), concentrations of $\mathrm{Cd}, \mathrm{Co}, \mathrm{Cu}, \mathrm{Ni}$, and $\mathrm{Pb}$ were analyzed by inductively coupled plasma mass spectrometry (ICP-MS, Agilent 7500CX, Agilent Technologies, Palo Alto, USA) and concentration of $\mathrm{S}$ was measured by an elemental analyzer (Carlo Erba, Trent, Italy). The accuracy of the analysis was assessed by using standard samples (GSD-12 and GSS-1) and the recovery of each element was in the range of $85 \%-110 \%$. Duplicates were analyzed on $10 \%$ of the sediment samples and the standard deviations were within $\pm 5 \%$ of means.

\section{Fuzzy model set}

For fuzzy synthetic evaluation, seven types of heavy metals ( $\mathrm{Ba}, \mathrm{Cd}, \mathrm{Cr}, \mathrm{Co}, \mathrm{Cu}, \mathrm{Pb}$, and $\mathrm{Ni}$ ) were selected as risk indicators to assess the environmental quality of sediments. The classification of pollution degree for the indicators was firstly established on the Environmental Quality Standards for Soils of China (GB15618-1995) (CEPA, 1995). The environmental quality of the sediments was classified on five levels: Class I (good), Class II (clean), Class III (slightly polluted), Class IV (moderately polluted), and Class $\mathrm{V}$ (heavily polluted). The classification system was then corrected based on soil background values in Shaanxi Province (EMC, 1990), and previous studies (Tan et al., 2006; Lourenço et al., 2010) (Table I).
Membership functions of heavy metals to criteria at five degrees were established according to the trapezoidal algorithm (Lourenço et al., 2010), namely:

$r_{i j}\left(c_{i l}\right)= \begin{cases}1 & c_{i l} \leq v_{i j} \\ \frac{c_{i l}-v_{i j+1}}{v_{i j}-v_{i j+1}} & v_{i j}<c_{i l}<v_{i j+1} \\ 0 & c_{i l} \geq v_{i j+1}\end{cases}$

if $j=1$,

$r_{i j}\left(c_{i l}\right)= \begin{cases}0 & v_{i j+1} \leq c_{i l} \leq v_{i j-1} \\ \frac{c_{i l}-v_{i j-1}}{v_{i j}-v_{i j-1}} & v_{i j-1}<c_{i l}<v_{i j} \\ \frac{c_{i l}-v_{i j+1}}{v_{i j}-v_{i j+1}} & v_{i j}<c_{i l}<v_{i j+1}\end{cases}$

if $j=2,3$ and 4 ,

$r_{i j}\left(c_{i l}\right)= \begin{cases}0 & c_{i l} \leq v_{i j-1} \\ \frac{c_{i l}-v_{i j-1}}{v_{i j}-v_{i j-1}} & v_{i j-1}<c_{i l}<v_{i j} \\ 1 & c_{i l} \geq v_{i j}\end{cases}$

if $j=5$, where $c_{i l}$ is the measured value for the $i$ th heavy metal at the $l$ th monitoring site, $v_{i j}$ is the standard value of the $i$ th heavy metal at the $j$ th level $(i=1,2, \ldots, n ; j=1,2, \ldots, m), r_{i j}$ is the membership degree of the $i$ th heavy metal at the $j$ th level, and $r_{i j} \in[0,1]$; the smaller the membership degree, the better the environmental quality. Thus, the fuzzy matrix $(R)$ was obtained as the following equation:

$R=\left(r_{i j}\right)_{n \times m}=\left(\begin{array}{cccc}r_{11} & r_{12} & \cdots & r_{1 m} \\ r_{21} & r_{22} & \cdots & r_{2 m} \\ \vdots & \vdots & \vdots & \vdots \\ r_{n 1} & r_{n 2} & \cdots & r_{n m}\end{array}\right)$

Entropy theory is an objective way to determine the weight of an index, and it has been widely used in environmental assessment, economy, engineering, and

TABLE I

Environmental quality classes for heavy metals in the sediments

\begin{tabular}{|c|c|c|c|c|c|c|c|c|}
\hline Class & Criterion & $\mathrm{Ba}$ & $\mathrm{Cd}$ & $\mathrm{Co}$ & $\mathrm{Cr}$ & $\mathrm{Cu}$ & $\mathrm{Ni}$ & $\mathrm{Pb}$ \\
\hline & & \multicolumn{7}{|c|}{$\mathrm{mg} \mathrm{kg}^{-1}$} \\
\hline I & Good & 450 & 0.1 & 5 & 60 & 20 & 25 & 15 \\
\hline II & Clean & 480 & 0.2 & 12 & 90 & 35 & 35 & 25 \\
\hline III & Slightly polluted & 550 & 0.4 & 20 & 150 & 55 & 55 & 35 \\
\hline IV & Moderately polluted & 650 & 0.7 & 40 & 250 & 120 & 120 & 70 \\
\hline $\mathrm{V}$ & Heavily polluted & 800 & 1.5 & 80 & 400 & 250 & 200 & 150 \\
\hline
\end{tabular}


finance (Tan et al., 2006). However, some elements with low concentration but high toxicity are ignored (Yang et al., 2009; Zhang et al., 2014). To address this problem, Hakanson (1980) introduced a toxic response factor, improved by Xu et al. (2008), which could be used to determine and define the degree of metal pollution in sediments objectively and precisely. In this study, a method of weighted stacking between entropy weight and toxicity coefficient was conducted to scale the synthetic effect of the toxicity and concentration of metals. For each evaluation indicator, the entropy $\left(H_{i}\right)$ and weight $\left(W_{i}\right.$ and $\left.W_{i}^{\prime}\right)$ for the $i$ th heavy metal at each monitoring site can be obtained by the level analysis method as follows:

$H_{i}=-k \sum_{l=1}^{p}\left(C_{i l} / \sum_{l=1}^{p} C_{i l}\right) \times \ln \left(C_{i l} / \sum_{l=1}^{p} C_{i l}\right)$

$W_{i}=\left(1-H_{i}\right) /\left(n-\sum_{i=1}^{n} H_{i}\right)$

$W_{i}^{\prime}=T_{i} W_{i} / \sum_{i=1}^{n} T_{i} W_{i}$

where $C_{i l}$ is the normalization value of the $i$ th heavy metal at the $l$ th monitoring site; $k$ is a parameter, calculated by $k=1 / \ln p$, where $p$ is the number of monitoring sites (74 in this study); $W_{i}$ is the weight for the $i$ th heavy metal using the entropy method; $W_{i}^{\prime}$ is the modified weight for the $i$ th heavy metal considering toxicity; and $T_{i}$ is the toxic response factor for the $i$ th heavy metal (30 for $\mathrm{Cd}, 2$ for $\mathrm{Cr}$, and 5 for $\mathrm{Ba}$, Co, $\mathrm{Cu}, \mathrm{Ni}$, and $\mathrm{Pb})$. Thus, the weight matrix $(W)$ at each monitoring site was obtained as follows:

$W=\left\{W_{1}^{\prime}, W_{2}^{\prime}, \cdots, W_{n}^{\prime}\right\}$

The algorithm of fuzzy synthetic matrix $(B)$ is similar to that of common matrix multiplication. The result $B$ can be obtained via multiplying the weight matrix $(W)$ by the fuzzy matrix $(R)$ as:

$B=W \times R=\left\{b_{1}, b_{2}, \cdots, b_{m}\right\}$

Evaluation result is defined as Class $=\max \left(b_{j}\right)$ $(j=1,2, \ldots, m)$, where $b_{j}$ is the product of the modified weight of $i$ th heavy metal and the fuzzy matrix and $\max \left(b_{j}\right)$ is the maximum value of $b_{j}$. Then, the $\max \left(b_{j}\right)$ was used to identify the environmental quality class of sediments in the study area.

\section{Statistical analysis}

Correlation analysis (CA), cluster analysis, princi- pal component analysis (PCA), and the risk analysis using PLI and RI index were performed using SPSS 16.0. The land use pattern was sourced from landsat TM images using ENVI 4.1 and ArcGIS 10.0. Spatial analysis was applied with ArcGIS 10.0. Model designs of the fuzzy synthetic method and BPNN were performed using Matlab 7.0. Concentrations of heavy metals were transformed into logarithmic values to elucidate the normal distribution characteristics and avoid distortions in the data distribution and low levels of significance (Shapiro-Wilk determination, $P<0.05$ ).

\section{RESULTS AND DISCUSSION}

\section{Enrichment of heavy metals in sediments}

Sediment $\mathrm{pH}$ in the study area was slightly alkaline, with an average value of $8.46 \pm 0.25$. The contents of TOC $\left(5.7 \pm 3.2 \mathrm{~g} \mathrm{~kg}^{-1}\right)$ and LOI $(1.12 \% \pm$ $0.01 \%$ ) in sediments remained at a low level with little variation. The sediment samples mainly contained sand $(72.93 \%)$. Table II summarizes the statistical attributes of concentrations of heavy metals as well as $\mathrm{Al}, \mathrm{P}, \mathrm{S}$, and $\mathrm{K}$ in sediments of the Fenghe River and the corresponding background values. Total concentrations of heavy metals from the investigated sites followed the order of $\mathrm{Ba}>\mathrm{Mn}>\mathrm{Cr}>\mathrm{V}>\mathrm{Pb}>\mathrm{Zn}>\mathrm{Co}$ $>\mathrm{Ni}>\mathrm{Cu}>\mathrm{Cd}$. Concentrations of $\mathrm{Cd}, \mathrm{Cu}, \mathrm{Ni}$, and $\mathrm{Zn}$ in sediments fluctuated greatly within the ranges of $0.3-2.2,2.3-115.5,2.6-60.1$, and $6.9-75.1 \mathrm{mg} \mathrm{kg}^{-1}$, respectively, and the variation coefficients of $\mathrm{Cd}(55.2 \%)$, $\mathrm{Cu}(90.8 \%), \mathrm{Ni}(43.2 \%)$, and $\mathrm{Zn}(53.7 \%)$ were relatively higher than those the other 6 heavy metals (from $12.2 \%$ to $21.1 \%$ ). Except for $\mathrm{Zn}$ and $\mathrm{Ni}$, the concentrations of heavy metals all exceeded the background values, especially for $\mathrm{Ba}\left(638.9 \mathrm{mg} \mathrm{kg}{ }^{-1}\right), \mathrm{Cd}(0.9 \mathrm{mg}$ $\mathrm{kg}^{-1}$ ), Co (22.1 $\left.\mathrm{mg} \mathrm{kg}^{-1}\right)$, Cr (93.0 $\mathrm{mg} \mathrm{kg}^{-1}$ ), and $\mathrm{Pb}$ $\left(32.8 \mathrm{mg} \mathrm{kg}^{-1}\right)$, which were $1.3,9.0,2.1,1.5$, and 1.5 fold higher than their background values in Shaanxi Province (EMC, 1990), respectively. The results indicated that the main contribution to metal pollution in the study area was $\mathrm{Cd}$, and significant enrichment of $\mathrm{Co}, \mathrm{Cr}$ and $\mathrm{Pb}$ in sediments was also found.

Correlation analysis showed that sediment $\mathrm{pH}$ was significantly $(P<0.05)$ correlated with each metal concentration, and was correlated with median grain size and TOC $(P<0.05)$ of sediment as well. The relationship between sediment TOC and each metal concentration was poor. It is well-established that sediment pH strongly influences the solubility of sediment metals (Zhang et al., 2014). Therefore, the sediment $\mathrm{pH}$ was employed as a covariate in the spatial analysis by using the co-kriging method (Wu et al., 2006). The 
spatial variation of some sediment metals with high concentrations is shown in Fig. 2. Significant enrichment of $\mathrm{Al}, \mathrm{Ba}, \mathrm{Cr}, \mathrm{Co}, \mathrm{Cu}, \mathrm{Mn}, \mathrm{Ni}$, and $\mathrm{Pb}$ in sediments was found in the midstream and downstream of the Fenghe River. In the headwater stream, concentration of $\mathrm{Cu}$ was enriched, while that in other sections was relatively lower. The elevated concentration of heavy metals could be related to local point sources (Fig. 1), due to the frequent activities and rapid urbanization in this area.

\section{Multivariate statistical analyses}

Principal component analysis (PCA) was performed to analyze source profiles of sediment metals by applying a varimax rotation with Kaiser normal- ization. The results of Kaiser-Meyer-Olkin (KMO) algorithm (0.648) and Bartlett algorithm (380.444, $P<$ 0.01 ) showed that the data measured in the present study were suitable for analysis (Varol, 2012). Table III summarizes the results of explained variance and factor loadings. A total of 4 components had been extracted, and $98.68 \%$ of the cumulative variance could be demonstrated. Principal component (PC) 1 accounted for $51.59 \%$ of the total variance and loaded heavily on $\mathrm{Cd}, \mathrm{Al}$, and $\mathrm{Pb}$. PC 2 explained $23.01 \%$ of the total variance and loaded on $\mathrm{Co}, \mathrm{S}$, and $\mathrm{Zn}$. PC 3, dominated $\mathrm{K}, \mathrm{Mn}$, and $\mathrm{V}$, and $\mathrm{PC} 4$, dominated by $\mathrm{Cu}$ and $\mathrm{P}$, accounted for $14.21 \%$ and $9.88 \%$ of the total variance, respectively. The relationships among factors could be more easily seen in Fig. 3a with a three-dimensional

TABLE II

Statistical attributes of concentrations of heavy metals as well as Al, P, S, and K in sediments of the Fenghe River and the corresponding background values

\begin{tabular}{|c|c|c|c|c|c|c|c|c|c|c|c|c|c|c|}
\hline Parameter $^{\mathrm{a})}$ & $\mathrm{Ba}$ & $\mathrm{Cd}$ & $\mathrm{Co}$ & $\mathrm{Cr}$ & $\mathrm{Cu}$ & $\mathrm{Ni}$ & $\mathrm{Mn}$ & $\mathrm{Pb}$ & $\mathrm{V}$ & $\mathrm{Zn}$ & $\mathrm{Al}$ & $\mathrm{P}$ & $\mathrm{S}$ & K \\
\hline & & & & & & & & \multicolumn{7}{|c|}{$\mathrm{mg} \mathrm{kg}^{-1}$} \\
\hline Min. & 434.6 & 0.3 & 11.7 & 53.2 & 2.3 & 2.6 & 466.9 & 20.6 & 51.7 & 6.9 & $4.1 \times 10^{4}$ & 541.1 & 198.7 & 17.1 \\
\hline Max. & 995.2 & 2.2 & 35.4 & 118.9 & 115.5 & 60.1 & 807.2 & 43.0 & 90.8 & 75.1 & $15.5 \times 10^{4}$ & 1056.8 & 496.3 & 27.6 \\
\hline $\mathrm{SD}$ & 134.3 & 0.5 & 4.7 & 12.5 & 24.5 & 10.6 & 83.5 & 4.1 & 10.1 & 20.7 & $2.9 \times 10^{4}$ & 131.7 & 81.5 & 2.2 \\
\hline $\mathrm{CV}(\%)$ & 20.6 & 55.2 & 21.1 & 13.3 & 90.8 & 43.2 & 13.7 & 12.2 & 13.5 & 53.7 & $26.5 \times 10^{4}$ & 17.9 & 21.5 & 10.1 \\
\hline GM & 638.9 & 0.9 & 22.1 & 93.0 & 20.2 & 21.6 & 605.4 & 32.8 & 74.1 & 31.6 & $10.5 \times 10^{4}$ & 723.2 & 370.1 & 21.6 \\
\hline BV & 480.0 & 0.1 & 10.6 & 62.5 & 21.4 & 28.8 & 557.0 & 21.4 & 66.9 & 69.4 & $5.8 \times 10^{4}$ & $\mathrm{NA}^{\mathrm{b})}$ & NA & NA \\
\hline $\mathrm{EF}$ & 1.3 & 9.5 & 1.9 & 1.4 & 1.2 & 0.8 & 1.1 & 1.4 & NA & 0.5 & 1.7 & NA & NA & NA \\
\hline
\end{tabular}

a) Min. = minimum; Max. = maximum; $\mathrm{SD}=$ standard deviation; $\mathrm{CV}=$ coefficient of variation; $\mathrm{GM}=$ geometric mean; $\mathrm{BV}=$ background value; $\mathrm{EF}=$ enrichment factor.

b) Not available.
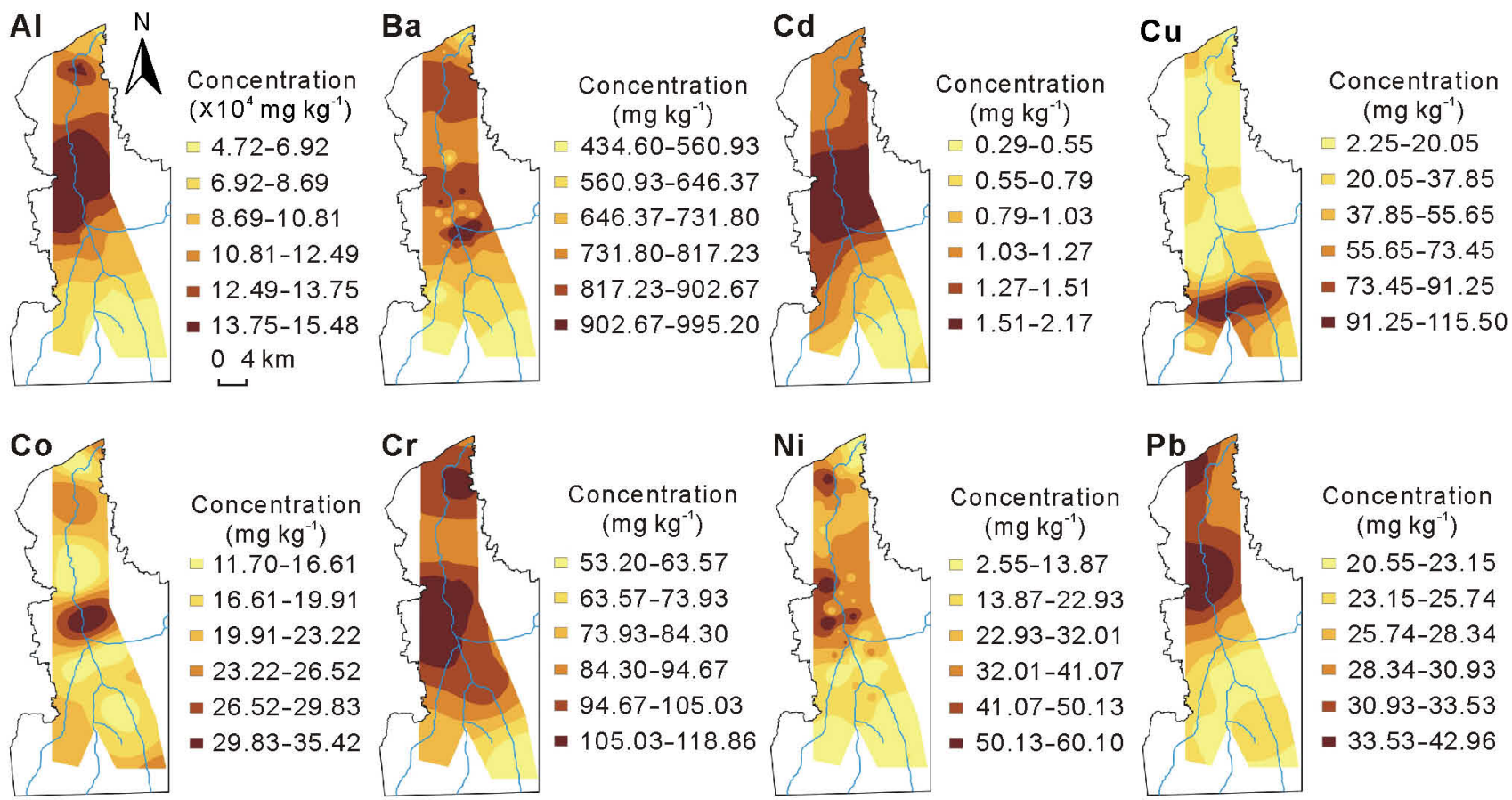

Fig. 2 Spatial distribution of some sediment metals in the Fenghe River. 

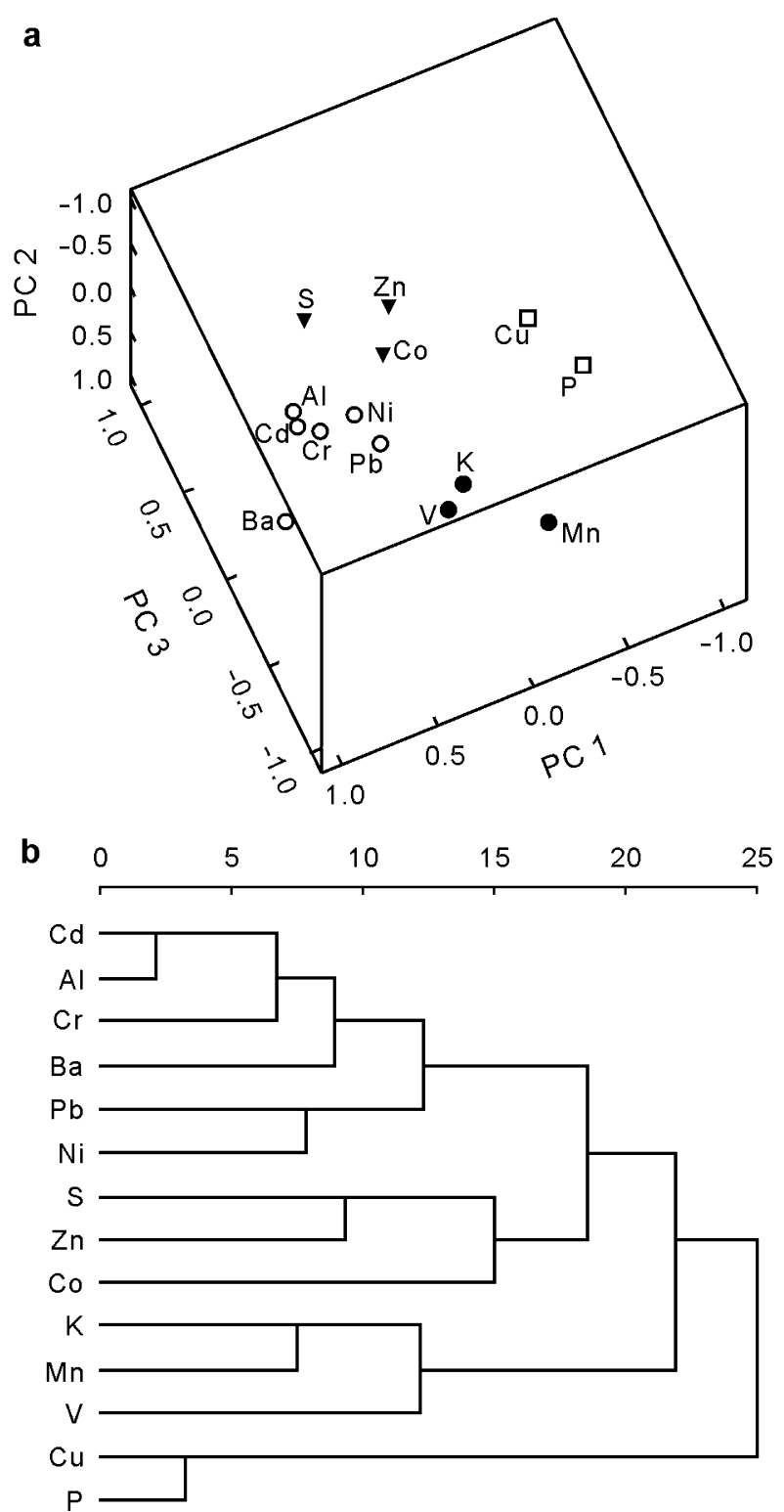

Fig. 3 Results of multivariate statistical analyses for heavy metals as well as Al, P, S and $\mathrm{K}$ in sediments of the Fenghe River: (a) matrix of principal component (PC) loadings of these elements in sediments and (b) clustering tree of these elements in sediments based on the ward method.

space. Four groups can be classified according to the concentrations of heavy metals as well as $\mathrm{Al}, \mathrm{P}, \mathrm{S}$ and $\mathrm{K}$ in sediments using the ward method (Fig. 3b). Group I comprised $\mathrm{Al}, \mathrm{Ba}, \mathrm{Cd}, \mathrm{Cr}, \mathrm{Ni}$, and $\mathrm{Pb}$, Group II comprised Co, S, and Zn, Group III comprised K, Mn, and $\mathrm{V}$, and Group IV comprised $\mathrm{Cu}$ and P. Each group of elements may have similar source or releasing principles in sediments (Varol, 2011), being closely related to the production of industry and agriculture in the study area.

Based on the PCA and cluster analyses, four possible pollution sources had been identified (Fig. 3). Sediments near the factory activity enrich high levels of me-
TABLE III

Rotated principal component matrix and factor loadings for heavy metals as well as $\mathrm{Al}, \mathrm{P}, \mathrm{S}$ and $\mathrm{K}$ in sediments of the Fenghe River

\begin{tabular}{lrrrr}
\hline Element & \multicolumn{3}{c}{ Principal component } \\
\cline { 2 - 5 } & \multicolumn{1}{c}{2} & \multicolumn{1}{l}{3} & \multicolumn{1}{c}{4} \\
\hline $\mathrm{Al}$ & 0.736 & 0.002 & -0.056 & -0.280 \\
$\mathrm{Ba}$ & 0.371 & -0.149 & -0.017 & -0.070 \\
$\mathrm{Cd}$ & 0.836 & -0.082 & -0.078 & 0.537 \\
$\mathrm{Co}$ & -0.015 & 0.604 & 0.229 & 0.195 \\
$\mathrm{Cr}$ & 0.388 & 0.110 & 0.107 & 0.107 \\
$\mathrm{Cu}$ & -0.806 & 0.107 & -0.042 & 0.581 \\
$\mathrm{~K}$ & 0.027 & -0.349 & 0.436 & 0.297 \\
$\mathrm{Mn}$ & -0.242 & -0.750 & 0.589 & 0.180 \\
$\mathrm{Ni}$ & 0.218 & 0.146 & -0.026 & -0.365 \\
$\mathrm{P}$ & -0.626 & 0.347 & 0.275 & 0.359 \\
$\mathrm{~Pb}$ & 0.701 & 0.130 & -0.097 & -0.174 \\
$\mathrm{~S}$ & 0.398 & 0.669 & 0.617 & 0.106 \\
$\mathrm{~V}$ & 0.146 & -0.625 & 0.227 & -0.132 \\
$\mathrm{Zn}$ & 0.099 & 0.578 & 0.424 & 0.100 \\
Eigenvalue & 3.713 & 2.108 & 1.279 & 1.209 \\
Percentage of total & 51.592 & 23.005 & 14.206 & 9.879 \\
variance (\%) & & & & \\
Cumulative variance (\%) & 51.592 & 74.597 & 88.803 & 98.682 \\
\hline
\end{tabular}

tals, and serious pollution of $\mathrm{Cd}, \mathrm{Ba}$, and $\mathrm{Pb}$ in sediments is affected mostly by the industrial application (Yang et al., 2009; Zeng and Wu, 2009). Field investigation showed that a lot of paper plants are distributed in the midstream and downstream, resulting in large amounts of the waste solids and industrial sewages containing excess aluminous coagulants. As is known to all, the aluminous coagulants in the process of paper producing contain many hazardous substances such as Al, Cd, and $\mathrm{Pb}$ (Wang et al., 2013). Al received elevated weighting than other elements in PC 1; therefore, it was clear that the first pollution factor was related to the pollution source from paper plants. High level of $\mathrm{Zn}$ is mainly linked to manure application, and fertilizers and pesticides usually contain a lot of $\mathrm{S}$ (Wu et al., 2006), suggesting that the second pollution factor denoted agronomic practices. As one of characteristic elements of natural sources, Mn has been used to scale the influence of humans on metal accumulation in sediments, and $\mathrm{V}$ concentration greatly depends on the background value (Amorosi et al., 2013). Results showed that the third pollution factor was mainly linked with the natural sources. $\mathrm{Cu}$ was the most enriched metals in the headwater stream of the Fenghe River, with a top coefficient of variation $(90.8 \%)$. Generally, $\mathrm{Cu}$ could be released by the sanitary sewage and frequently anthropogenic activities (Varol, 2011). As the minor enriched elements in PC 4, $\mathrm{P}$ was primarily from phosphate detergents and orga- 
nic fertilizers. In recent years, the ecological tourism in this area grew rapidly, resulting in large amounts of household wastes and domestic sewages discharged into the Fenghe River. Results indicated that the fourth pollution factor was primarily related to tourism.

\section{Fuzzy synthetic evaluation}

The assessment of pollution degree of sediment metals is a complex work with a series of difficulties in its application, and the selection of appropriate indicators is a key step (Grygar et al., 2013). Several studies showed that natural concentrations of sediment metals are significantly affected by grain size of sediments (Zeng and Wu, 2009; Amorosi et al., 2013). Correlation analysis showed that concentrations of $\mathrm{Mn}$ and $\mathrm{V}$ were closely related with median grain size of sediments $\left(R^{2}=0.238\right.$ for $\mathrm{Mn}, R^{2}=0.304$ for $\left.\mathrm{V}, P<0.05\right)$, indicating that the concentrations of $\mathrm{Mn}$ and $\mathrm{V}$ were mainly controlled by the grain size of sediments as a result of natural weathering process in the study area. The metal $\mathrm{V}$ is relatively immobile in the aquatic environment, and frequently used as a geochemical normalizer (Amorosi et al., 2013). Therefore, data are normalized using $\mathrm{V}$ to evaluate the anthropogenic influences on the enrichment of sediment metals based on the EF (Zeng and $\mathrm{Wu}, 2009$ ).

As shown in Table II, the EF values of $\mathrm{Cd}, \mathrm{Al}$, and Co were 9.5, 1.7, and 1.9, respectively, indicating that the concentrations of these metals $(\mathrm{EF}>1.5)$ were a major concern in the study area (Amorosi et al., 2013). The $\mathrm{EF}$ values of $\mathrm{Ba}, \mathrm{Cr}$, and $\mathrm{Pb}$ were close to 1.5, while the EF values of the remaining metals were relatively lower. As recommended by Grygar et al. (2013), the EF values between 0.5 and 1.5 suggested that the enrichment of elements could be attributed to natural weathering process. Based on statistical analysis, concentrations of $\mathrm{Ba}, \mathrm{Cr}, \mathrm{Pb}$, and $\mathrm{Ni}$ were significantly correlated to concentrations of $\mathrm{Cd}$ and $\mathrm{Al}$. With a great spatial variation, high concentration of $\mathrm{Cu}$ was observed in the headwater stream of the Fenghe River. Therefore, the enrichment of $\mathrm{Ba}, \mathrm{Cr}, \mathrm{Cu}, \mathrm{Pb}$, and $\mathrm{Ni}$ could also be attributed to diffuse pollution sources instead of the natural weathering process.

It was imperative to establish a hierarchical structure for the comprehensive evaluation system. Because there are no available standard and toxicity coefficient of $\mathrm{Al}$ in the Environmental Quality Standards for Soils of China (GB 15618-1995) (CEPA, 1995) and related references, the sediment quality with respect to $\mathrm{Al}$ was not evaluated in this study. The entropy for $\mathrm{Ba}, \mathrm{Cd}$, $\mathrm{Co}, \mathrm{Cr}, \mathrm{Cu}, \mathrm{Ni}$, and $\mathrm{Pb}$ were $0.968,0.989,0.957,0.941$, $0.996,0.972$, and 0.903 , respectively, and weights for these 7 indicators were in the order of $\mathrm{Pb}(0.330)>\mathrm{Cd}$ $(0.225)>\mathrm{Co}(0.146)>\mathrm{Ba}(0.109)>\mathrm{Ni}(0.095)>\mathrm{Cr}$ $(0.080)>\mathrm{Cu}(0.015)$. Results indicated that the main pollution factors in sediments of the study area were $\mathrm{Pb}$ and $\mathrm{Cd}$, which were significantly correlated to the activities of paper plants.

The fitness of sediments from the monitoring sites was classified into four groups based on the fuzzy synthetic evaluation model (Fig.4). Eleven sites were heavily polluted (Class V), and 32 sites moderately polluted (Class IV). Five sites were not polluted (Class II, clean), of which 2 sites were situated in the headwater stream and 3 sites were located in the downstream. The other 26 sites were polluted to some degree and fell into Class III (slightly polluted), suggesting that there was a relatively high degree of metal pollution in sediments of the Fenghe River.

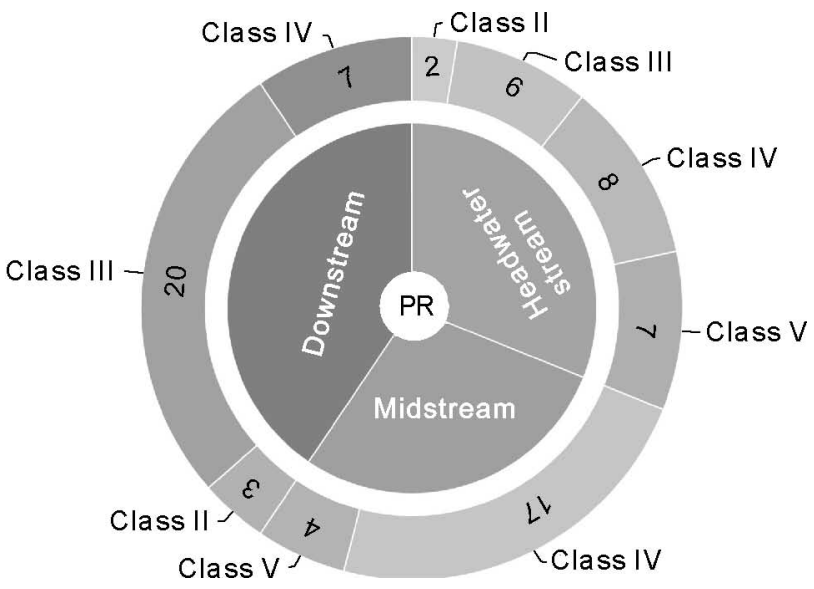

Fig. 4 Risk classification of heavy metals (Ba, Cd, Co, Cr, Cu, $\mathrm{Ni}$, and $\mathrm{Pb}$ ) in sediments of the Fenghe River based on the fuzzy synthetic evaluation model. The numbers are the amounts of sampling sites fell in each class. $\mathrm{PR}=$ pollution risk.

Most monitoring sites in the headwater stream fell into the polluted class (Fig. 4). Among them, 6, 8 and 7 sites belonged to Class III (slightly polluted), Class IV (moderately polluted), and Class V (heavily polluted), respectively. Although there were 2 sites in this area affiliated with Class II (clean), but their membership degree scores in the polluted class were on the rise (Fig. 5). In the midstream, all sites studied were suffering from the heavy metal pollution (Classes IV and V), 17 sites belonged to Class IV (moderately polluted) and 4 sites fell into Class V (heavily polluted). This area has a lot of paper plants (Fig. 1), which was closely related to the sediment metal pollution in the Fenghe River. Obviously, this area was of high risk and should be paid more attention. In the downstream, 3 sites belonged to the Class II (clean), and the remaining 27 sites all fell into the polluted classes (Classes III and 
V).

The results of ecological risk of sediment metals based on PLI, RI, and BPNN, 3 commonly used methods to evaluate the heavy metal pollution (Subida et al., 2013) are shown in Fig. 6. The PLI assessment showed that almost all of the samples were at moderate pollution $(1<\mathrm{PLI}<2)$. The RI assessment presented that significant enrichment of heavy metals was found in midstream and in the upper part of the downstream
(300 < RI $<600$, high pollution) (Yang et al., 2009). The BPNN assessment indicated that most areas in the study area fell into Class IV (moderately polluted), and the catchment areas in the midstream were heavily polluted (Class V) (Fig. 6). Compared to the conventional methods, the fuzzy synthetic evaluation model was successfully used to map the spatial changes of membership degree of different risk grades in the study area. In order to provide an appropriate evaluation
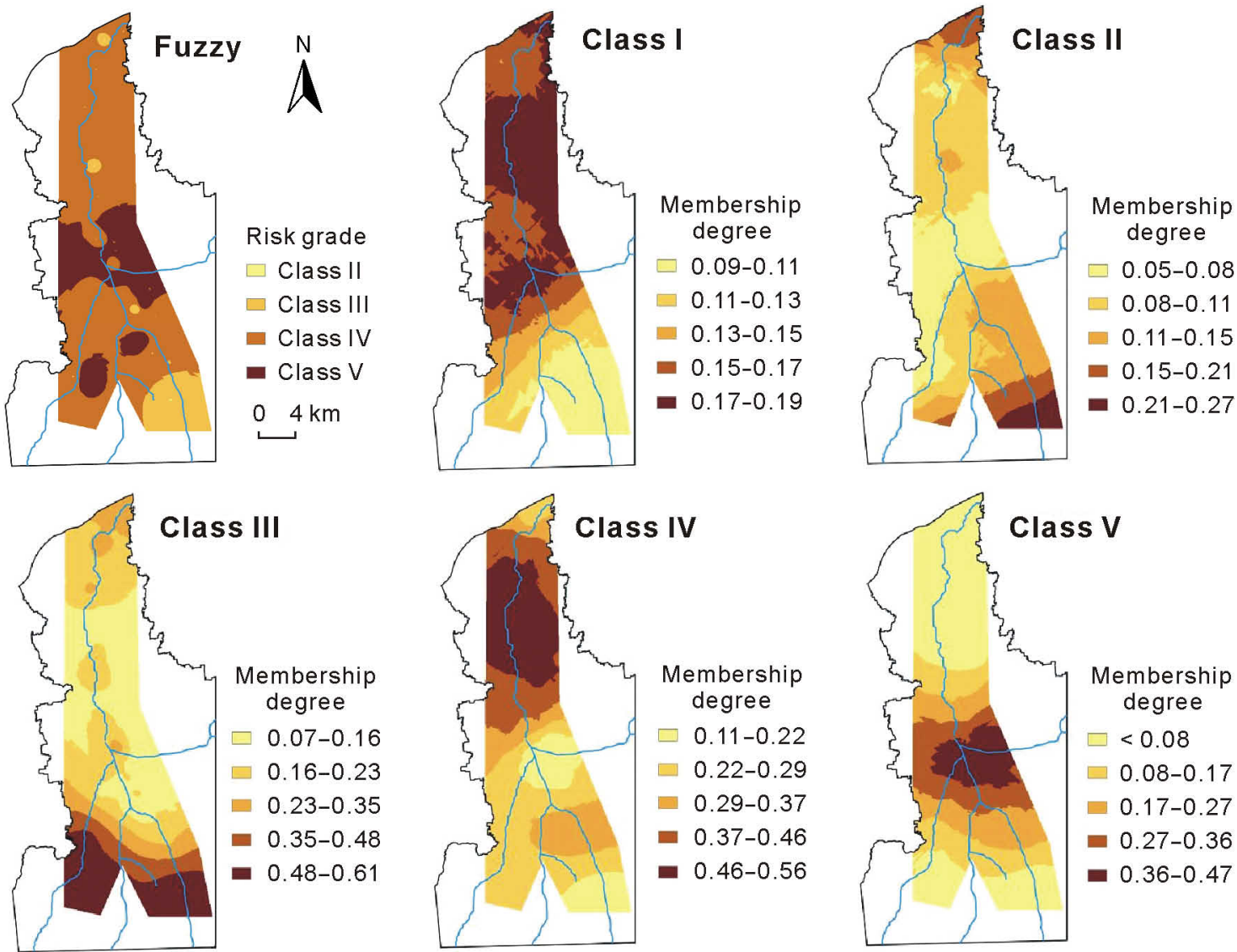

Fig. 5 Membership degree of different risk grades in each class for heavy metals in sediments of the Fenghe River using the fuzzy synthetic evaluation model.
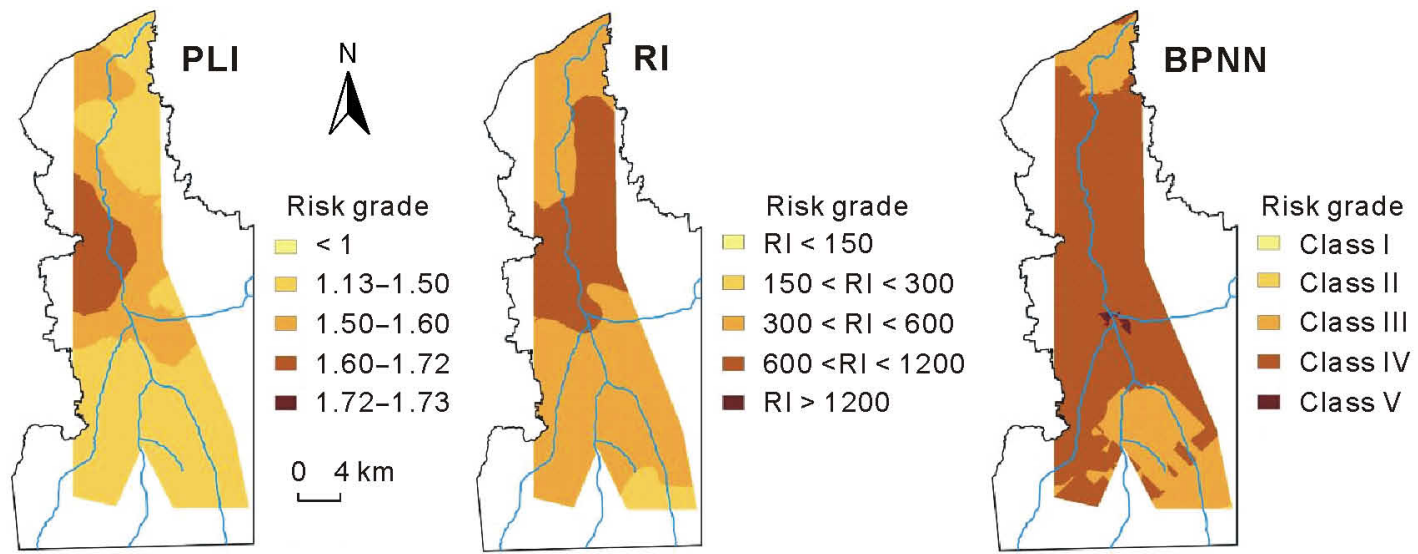

Fig. 6 Risk assessment of heavy metals in sediments of the Fenghe River using pollution load index (PLI), potential risk index (RI), and back-propagation neural network (BPNN) model. 
of the fate and transport of heavy metals from anthropogenic sources and the ecological risk of sediment metals, a comprehensive approach that can integrate spatial heterogeneity, toxicity coefficient, background value, and $\mathrm{EF}$ should be taken into account.

\section{CONCLUSIONS}

Moderate pollution of $\mathrm{Cd}, \mathrm{Al}$, and $\mathrm{Co}(\mathrm{EF}>1.5)$ was found in the study area. Significant enrichment of heavy metals in the midstream and pollution of $\mathrm{Cd}(\mathrm{EF}$ $=9.5$ ) were of prior concern for pollution control. Four main sources were identified and the paper plants were the most crucial pollution source. Sixty-nine of the 74 investigated sites fell into Classes III-V based on the fuzzy synthetic evaluation model. The proposed model yielded satisfactory results in risk assessment of sediment metals in the study area. Results of these study may help the sediment pollution management in the study area and other regions.

\section{ACKNOWLEDGEMENTS}

This study was supported by the National Natural Science Foundation of China (Nos. 41030744 and 41173123). Thanks also to the reviewers for their helpful suggestions and comments on the manuscript.

\section{REFERENCES}

Amorosi A, Sammartino I, Sarti G. 2013. Background levels of potentially toxic metals from soils of the Pisa coastal plain (Tuscany, Italy) as identified from sedimentological criteria. Environ Earth Sci. 69: 1661-1671.

CEPA (Chinese Environmental Protection Administration). 1995. Environmental Quality Standard for Soils of China (GB15618-1995) (in Chinese). CEPA, Beijing.

Environmental Monitoring of China (EMC). 1990. Chinese Soil Element Background Values (in Chinese). China Environment Science Press, Beijing.

Grygar T M, Nováková T, Bábek O, Elznicová J, Vadinová N. 2013. Robust assessment of moderate heavy metal contamination levels in floodplain sediments: A case study on the Jizera River, Czech Republic. Sci Total Environ. 452: 233245.
Hakanson L. 1980. An ecological risk index for aquatic pollution control. A sedimentological approach. Water Res. 14 975-1001.

Lourenço R W, Barbosa Landim P M, Rosa A H, Roveda J A F, Martins A C G, Fraceto L F. 2010. Mapping soil pollution by spatial analysis and fuzzy classification. Environ Earth Sci. 60: 495-504.

Subida M, Berihuete A, Drake P, Blasco J. 2013. Multivariate methods and artificial neural networks in the assessment of the response of infaunal assemblages to sediment metal contamination and organic enrichment. Sci Total Environ. 450-451: 289-300.

Tan M Z, Xu F M, Chen J, Zhang X L, Chen J Z. 2006. Spatial prediction of heavy metal pollution for soils in peri-urban Beijing, China based on fuzzy set theory. Pedosphere. 16: 545-554.

Varol M. 2011. Assessment of heavy metal contamination in sediments of the Tigris River (Turkey) using pollution indices and multivariate statistical techniques. J Hazard Mater. 195: $355-364$.

Viers J, Dupré B, Gaillardet J. 2009. Chemical composition of suspended sediments in World Rivers: New insights from a new database. Sci Total Environ. 407: 853-868.

Walling D E. 2006. Human impact on land-ocean sediment transfer by the world's rivers. Geomorphology. 79: 192-216.

Wang D Q, He Y L, Liang J D, Liu P, Zhuang P Y. 2013. Distribution and source analysis of aluminum in rivers near Xi'an City, China. Environ Monit Assess. 185: 1041-1053.

Wu J, Norvell W A, Welch R M. 2006. Kriging on highly skewed data for DTPA-extractable soil Zn with auxiliary information for $\mathrm{pH}$ and organic carbon. Geoderma. 134: 187-199.

Xu Z Q, Ni S J, Tuo X G, Zhang C J. 2008. Calculation of heavy metals' toxicity coefficient in the evaluation of potential ecological risk index. Environ Sci Technol (in Chinese). 31: 112115.

Yang Z F, Wang Y, Shen Z Y, Niu J F, Tang Z W. 2009. Distribution and speciation of heavy metals in sediments from the mainstream, tributaries, and lakes of the Yangtze River catchment of Wuhan, China. J Hazard Mater. 166: 11861194.

Zeng H A, Wu J L. 2009. Sedimentary records of heavy metal pollution in Fuxian Lake, Yunnan Province, China: intensity, history, and sources. Pedosphere. 19: 562-569.

Zhang C, Yu Z G, Zeng G M, Jiang M, Yang Z Z, Cui F, Zhu M Y, Shen L Q, Hu L. 2014. Effects of sediment geochemical properties on heavy metal bioavailability. Environ Int. 73: 270-281.

Zhao H T, Li X Y. 2013. Risk assessment of metals in roaddeposited sediment along an urban-rural gradient. Environ Pollut. 174: 297-304. 